\title{
CORRESPONDENCE
}

\section{Genesis of genetics}

SIR - I find the current interest among biologists in the findings of Gorczynski and Steele ${ }^{1,2}$ somewhat surprising, since a report of Lamarckian inheritance was published about 3,000 years ago. It is written that:

"And Jacob took him rods of green poplar, and of the hazel and chestnut tree; and pilled white strakes in them, and made the white appear which was in the rods. And he set the rods which he had pilled before the flocks in the gutters in the watering troughs when the flocks came to drink, that they should conceive when they came to drink. And the flocks conceived before the rods, and brought forth cattle ringstraked, speckled, and spotted." 3

Were these findings ever reproduced? If so, would it not be more appropriate to speak of Jacobinic genetics?

\section{KIRSTEN FISCHER LINDAHL}

Basel Institute for Immunology,

Basel, Switzerland

1. Gorczynski, R.M. \& Steele, E.J. Proc. natn. Acad. Sci U.S.A. 77, 2871-2875 (1980).

2. Gorczynski, R.M. \& Steele, E.J. Nature 289, 678-68। (1981).

3. Genesis Ch. 30 , v. $37-39$.

\section{Ethics of genes}

SIR - It was with considerable surprise and no little confusion that I read Richard Dawkins' letter on genetic determination (Nature 12 February, p.528). In his commendable desire to dissociate himself from the National Front, he has left me totally perplexed about his actual views of the relation between genotype and phenotype. Near the end of his letter, he associates himself with the views of S.J. Gould, that the genetic basis of IQ is "trivially true, uninteresting, and unimportant', Yet earlier in the same letter, he says that genetics is sort of relevant since we may need to "fight all the harder', against genetic tendencies. But in his book The Selfish Gene, Dr Dawkins wrote that we are "robot vehicles blindly programmed to preserve the selfish molecules known as genes" (preface) and that these genes "swarm in huge colonies, safe inside gigantic lumbering robots, sealed off from the outside world . . . manipulating it by remote control. They are in you and me; they control us body and mind"' (p.21).

It really is very vexing. Just as I had learned to accept myself as a genetic robot and, indeed, felt relieved that I was not responsible for my moral imperfections, Dr Dawkins tells me that, after all, I must try hard to be good and that I am not as manipulated as I thought. This is a problem I keep having in my attempt to understand human nature. Professor

Wilson, in his book on sociobiology, assured me that neurobiology was going to provide me with "a genetically accurate and hence completely fair code of ethics"' (p.575). I was euphoric at the prospect that my moral dilemmas at last had a real prospect of resolution, when suddenly my hopes were dashed by an article in which Professor Wilson warned me against the naturalistic fallacy (New York Times 12 October, 1975). You can imagine my perplexity. I do wish I knew what to believe.

Perhaps I am just asking for that foolish consistency which Emerson tells us is the hobgoblin of small minds. But I see that Dr Dawkins himself is uncertain. I can only echo the question he asks in his letter. "Where on earth did the myth of the inevitability of genetic effects come from? Is it just a layman's fallacy, or are there influential professional biologists putting it about?',

ISADORE NABI

Museum of Comparative Zoology,

Harvard University, Cambridge,

Massachusetts, USA

\section{Cancer causation}

SıR - The Epstein-Swartz article which appeared in Naturel (and was essentially identical to the manuscript these authors presented at the autumn meetings of the American Public Health Association in Detroit) will elicit a variety of critical responses from those in the scientific community who are familiar with the specific aetiological links between cancer and the environment.

But here I would like to point out one major fallacy in the Epstein and Swartz piece - their premise (that lifestyle factors have been overstated in discussions of the aetiology of cancer) is based largely on the assumption that occupationally-induced cancers are more prevalent than previously thought. Epstein and Swartz criticize Dr Peto for dismissing "recent estimates of the importance of occupational carcinogens in a report by the US Public Health Service as exaggerated, unsound and unreasonable". This alleged "report" concluded that "as much as $20 \%$ or more" of cancers in the near term and future may reflect past exposure to specific carcinogens in the workplace.

Epstein and Swartz attempt to build up the credibility of this estimate by stating that the report was "prepared by nine named and internationally recognized experts in cancer epidemiology, statistics and carcinogens from three federal research agencies" and go on to add that "there is no basis whatsoever for recent unsubstantiated allegations by Peto and others that all or most of the authors of the government report have disowned or rejected it or its conclusions"

Epstein and Swartz are in error on two points in their discussion of occupational cancer and the so-called "estimates paper". First, nobody except those two authors and perhaps some regulators who wished to bolster their requests for more legal control over occupational chemicals has ever cited the " $20 \%$ " estimate in a serious, scientific context. Second, according to a detailed article by Ruth B. Schwartz in our publication $A C S H$ News and Views " "7 of the 10 scientists responsible for these statistics believe they may be incorrect. Only one scientist defends them as reasonable". Two could not be reached for their opinions. Ms Schwartz's conclusions were based on her in-depth discussions with the various "contributors",

Perhaps the most succinct evaluation of the "estimates paper" on which Epstein and Swartz rely so heavily was made by Sir Richard Doll: "I regard it (the "estimates paper') as scientific nonsense".

Elizabeth M. WhelaN

American Council on Science and Health, New York, USA

1. Epstein, S.S. \& Swartz, J.B. Nature 289, 127-130 (1981)

2. Schwartz, R.B. ACSH News and Views Nov/Dec (1980).

\section{Badger debate}

SIR - Dr Flowerdew's recent letter (Nature 26 February, p.742) makes me wonder what purpose the Mammal Society intended to serve by engaging in what can indeed now be called "the badger controversy". Dr Flowerdew says that the society spoke out because my report provided a "one-sided" interpretation of the evidence ("biased" in Dr Harris's letter of 11 December; Nature, p.532), and because my "categorical" conclusions and

recommendations did not take sufficient account of "the complexity of the problem" But in Dr Harris's letter it was also said that the society was intervening because it was necessary to correct certain "factually misleading statements" that 1 had made. Yet neither letter adduces any new "fact". Those that they use are the ones which I had assembled. Nor did either correspondent spell out any "anomalies" in the story other than those which I had considered. Dr Flowerdew now says that there is no unequivocal evidence that the gassing policy will produce a longterm solution, by which I presume he means stamp out the disease. But no one has ever claimed that it would. Above all, the Mammal Society, on whose behalf Drs Flowerdew and Harris have written, does not propose any alternative policy which the Government could pursue in order to lower the level of the reservoir of the bovine tubercle bacillus in the affected areas of the South West - the existence of which, as Dr Plowright pointed out (Nature 1/8 January, p.8), they first denied, but which in Dr Flowerdew's present letter he, or the Mammal Society, now seems to accept.

I intended no "attack on the Mammal Society and some of its members" - Dr Flowerdew's words - when I asked on what scientific authority the society based its presumed criticisms. The authorities on whom 
I myself relied were first, the many scientists and veterinary surgeons from the Ministry of Agriculture, Fisheries and Food whom I cross-examined during my enquiry; second, the three internationally-known students of animal disease whose help I acknowledged in my report - Sir William Henderson, FRCVS, FRS, Dr L. Goodwin, FRCP, FRS, and Dr W. Plowright, DVSc, FRCVS; and third, Professor T. McKeown, FRCP, well known for his studies of trends in tuberculosis and other diseases; the authorities in the Medical Research Council and Department of Health and Social Services who are concerned with tuberculosis; and Dr B.R. Cook, until recently with the New Zealand Ministry of Agriculture.

The officers of the Mammal Society may believe that their society is exempt from the usual convention that no scientific society has the licence to make corporate statements of a scientific nature on behalf of all its members. But if it is exempt, one is entitled to ask indeed, one is in duty bound to ask, since we are talking about a matter of animal and public health that is of international concern - who were the authorities on whom the Mammal Society leant, and whose counsel was denied me. Dr Flowerdew bluntly declares that the officers of the society were responsible for the statements that have appeared over his and Dr Harris's name. But apart from Dr Frazer, not one of the officers listed by the society is shown as having either a medical or veterinary qualification, and while some of its members, in particular Dr Neal, are well-known badger naturalists, none has written - unless in some unquoted journal - either on TB in cattle or on disease in badgers. Indeed, apart from $\mathrm{Dr}$ Neal's writings, I can find only one paper on badgers by any officer of the society, and that is a note by J.F.D. Frazer on badgers in Kent. The society's publications appear in the Mammal Review and in the form of "notes" in the Journal of Zoology, published by the Zoological Society of London.

Four of some 120 papers that have appeared in the lifetime of the Review concern badgers, and only seven deal with pathological matters (mainly ectoparasites - none deals with TB or with diseases in badgers); while only 15 of 311 "notes" concern badgers, and not one TB. In the circumstances, I find it more than a little strange that Dr Flowerdew suggests, presumably on behalf of his society, that the Ministry of Agriculture, Fisheries and Food should establish a Scientific Advisory Group "containing a small number of independent scientists such as wild-life epidemiologists and statisticians" - he offers no names - to "analyse the data in detail" for the ministry's Consultative Panel on Badgers and Tuberculosis, with the unfortunate imputation that in the view of the Mammal Society the ministry's scientific and veterinary officers are incompetent, and that their analyses of the data they collect cannot be relied upon.

University of East Anglia,

LORD ZUCKERMAN Norwich, UK

SIR - Why has the Mammal Society (Nature 26 February, p. 742) not attempted a reasoned reply to the criticisms contained in the letters by Dr Plowright (Nature 1/8 January, p.8) and myself (Nature 22 January, p.218), and by Zuckerman in his further article (Nature 19 February, p.628)?

If it is now accepted that the use of gassing by the ministry has substantially reduced herd breakdown in affected areas, its continuation is clearly indicated. There does not at present appear to be any other way of tackling this source of infection. Reduction of badger densities in affected areas not only reduces the chance of infecting cows because there are fewer badgers around, but offers the best hope of greatly reducing and possibly, as more is learnt, substantially eliminating tuberculosis from the badgers themselves. In this respect badgers are fortunate in that there is now no major external source of infection and the TB monitoring of dairy herds gives early warning of the presence of infected setts in a locality.

In their earlier letter the Mammal Society, while suggesting that "other more subtle factors may be significant", did not dispute that density might be of importance in the spread and maintenance of TB in the badgers. They have now gone back on this, stating that "there is no unequivocal evidence that TB in badgers is density-dependent". This statement is based on the maps of badger density and herd breakdowns included in the Zuckerman report $(p .68,70)$ which, they say, show that "TB is not only prevalent in areas of high density, but also in areas such as South Dartmoor where the badger population is very low". Had they referred to the subsidiary reliability diagram relating to the badger density map they would have found that the cluster of infections in South Dartmoor falls in an area classified on the reliability diagram as "mainly guesswork". They have completely ignored Zuckerman's discussion in his article of the statistical laws governing the propagation of infectious diseases, and his deduction that the establishment and maintenance of TB among badgers in an area is likely to be strongly density dependent, from which it follows that, as a matter of long-term policy, badger population densities should not be allowed to become excessive, as they certainly appear to be in parts of the South West at present.

The reactions to our other criticisms are similarly irresponsible and misleading. They dismiss Dr Plowright's letter with the comment that it "presented no new information nor did he answer any of the points we raised". The main point of my letter was to cast doubt on the Mammal Society's suggestion that the apparent success of the gassing campaign might be due to the decline of TB throughout the country. They appear now to have partially, but not wholly, conceded this point. They make much of the large decline from 5.5 to 3.2 per cent of herd breakdowns in Cornwall from 1975 to 1976 "highlighted" by my graph, and claim that it could not have been wholly produced by the gassing compaign. That there was a marked rise all over the country in 1975 , followed by a corresponding decline in 1976, was clearly shown by my graph, and was pointed out in my letter, but this does not preclude that a large part of the Cornish decline was due to the removal of infected badger groups, some of which may have been done by farmers without the cooperation of the ministry. In any case, if the Mammal Society wished to comment on the irregularities of the Cornish data they might better have directed attention to the disturbing rise of infection between January 1977 and September 1979 which, however, was matched by a substantial fall between October 1979 and March 1980.

There are two further glaring distortions of the evidence in their current letter. The first is my "contention", for which I gave reasons, that the 15 per cent of Cornish herd breakdowns attributed to badgers in the report was clearly much too low. That this contention was indeed correct was substantiated by the further information that Lord Zuckerman gave in his article. The Mammal Society accept this, but by lumping together the figures for 1974-75 and 1976-78 they conceal the progressive reduction in the proportion of "unknowns" and were able to claim that "since 1974 badgers were still only believed responsible for a minority of breakdowns"

A similar concealment of the full evidence occurs in their comment on the origins of infection from specific badger setts.

Zuckerman reported that he had been informed that for the whole of Cornwall 72 per cent of the 51 outbreaks definitely attributed to badgers were within 2 miles of infected setts and 33 per cent were within half a mile, and that for the West Penwith area the corresponding percentages were 97 and 47 . All that they state is that for the whole of Cornwall 28 per cent ( 100 minus 72 ) were attributed to setts more than 2 miles away and that badgers rarely travel this distance in areas of high density. A glance at the herd breakdowns map (p.20) of the report shows that the West Penwith area, which covers the western tip of Cornwall, contains the major pocket of infection and was clearly the source of the majority of the herd breakdowns.

Finally, in connection with their long and almost unintelligible argument on the effects of the moratorium on gassing, may I make it clear that neither Zuckerman nor I ever argued that "TB in badgers and cattle immediately increased as a result of the moratorium"; we merely reported the latest available data. Obviously there are time lags. The full effects of the moratorium cannot be properly assessed until data for a further year are available. Also in this connection, what is one to make of the statement: "This ... totally ignores the likelihood of natural cyclic trends in TB prevalence, as discussed in our original letter and the reply by Dr Yates"? There is no mention of cyclic trends either in their letter or in my reply!

FRANK YATES

Rothamsted Experimental Station,

Harpenden, UK

SIR - You have recently drawn attention to the controversy over the badger-gassing issue.

The Zuckerman report shows a rise and fall of tuberculosis in the South West and also in the rest of England from 1974 to 1980 . Some factor, common to the South West and the rest of England, must therefore be sought. I believe that factor is one which the Zuckerman report carefully avoids - the resumption of health-certification of the Irish cattle imports in June 1976 after nearly two years of importing TB-infected cattle into the United Kingdom during the Irish veterinary inspectors' strike.

The reluctance of the Animal Health Authority to suspend Irish cattle imports at that time contrasts sharply with their present enthusiasm to destroy badgers on scant evidence.

Peter H. Roberts

Compassion in World Farming,

Petersfield, UK 